\title{
SEIN UND ZEIT: LA LIBERTAD DEL DASEIN PARA SER-LIBRE COMO MISMIDAD. ANÁLISIS FENOMENOLÓGICO DE LA LIBERTAD Y LA MISMIDAD EN EL $\S 44^{*}$
}

\author{
Juan José Garrido Periñán** \\ http://orcid.org/0000-0002-7586-7579 \\ jjgarper@us.es
}

RESUMEN Este artículo de investigación intenta tematizar la mismidad del Dasein dentro de los límites intrínsecos del $\$ 44$ de Ser y Tiempo, en conexión plena con el existenciario verdad de la existencia, a fin de entender esta mismidad como un fenómeno eminente y ontológico de libertad. Tal derivación, en dirección a la libertad, mostrará que la conexión Dasein-Verdad solo puede ser realizada mediante un desarrollo de la mismidad del Dasein, entendida como un fenómeno relacionado con el "poner/quedar en libertad" y el "serlibre”. Este será, en último término, el objetivo de este artículo de investigación

Palabras-clave Mismidad, Libertad, Verdad de la Existencia, Dasein.

ABSTRACT In order to understand the Selfhood of Dasein as an eminent and ontological phenomenon of Freedom, this research seeks to thematise this Selfhood within the intrinsic limits of $\$ 44$ of the book 'Being and Time' in full connection with the existential truth of existence. Such Freedom will have to show that the nexus Dasein-truth can only be carried out in the wake

* Artigo submetido em 04/10/2018. Aprovado em 17/04/2019. La siguiente investigación se realiza bajo la cobertura del Proyecto I+D De Excelencia: "Dinámicas del cuidado y lo inquietante. Figuras de lo inquietante en el debate fenomenológico contemporáneo y las posibilidades de una orientación filosófica. Configuración teórica y metodológica" (FFI2017/83770-P), proporcionado por el Ministerio de Innovación, Ciencias y Universidades del Reino de España.

** Departamento de Estética e Historia de la Filosofía, Universidad de Sevilla. Sevilla, España. 
of a development of the Selfhood of the Dasein, a Selfhood understood as a phenomenon related to "set-free" and "being-free". Ultimately, this will be the objective of this research paper.

Keywords Selfhood, Freedom, Truth of existence, Dasein.

\section{Introducción}

La I Sección de la obra Ser y Tiempo ${ }^{1}$ cierra con un parágrafo (§ 44) que ha sido señalado por muchos intérpretes como muy importante (Guignon, 2011, pp. 79-105; García-Norro, 2015, pp. 187-195; Vigo, 2016, pp. 219-268), al considerar que, entre sus líneas, se expone una concepción magistral de la verdad, en tanto depurada de la interpretación tradicional - basada en la teoría de la adecuación del juicio con la cosa -, la cual coloca al Dasein como fundamento, ${ }^{2}$ en calidad de ente sumamente descubridor, del "ser-descubierto" [Entdecktheit] relativo al ente intramundano. En esta reconversión aleteiológica (Vigo, 2014b) ${ }^{3}$ del término verdad, muchos intérpretes del pensamiento de Heidegger han manifestado la valía sistemática y metódica que el $\S 44$ cumple sobre el mismo libro SuZ. Y no solo atendiendo a la singular posición del parágrafo en cuestión - diríamos, justo en la mitad -, sino porque en él se hace explícito, quizás, un término incluso más importante que la fundamentación co-originaria entre Dasein-verdad, esto es, el término: "verdad de la existencia" [Wahrheit der Existenz] (SuZ, p. 221). Siendo la verdad - del ser - un fenómeno relativo al modo de ser del Dasein, la verdad de la existencia es su modo óptimo, en la medida en que tal verdad de la existencia se hace cargo de una modalidad, singular a la propia idiosincrasia existencial del Dasein, que tiene que ver con la posibilidad de que este ente, en su "poder-ser" [sein-können], fácticamente arrojado, sea, justamente, aquello que es. O mejor: la verdad de la existencia

1 Como las citas, sean directas o indirectas, van a focalizarse en la obra de Heidegger Sein und Zeit, y con el fin de ganar claridad, nos permitimos la licencia de emplear la abreviatura SuZ (2002), para hacer mención de tal obra durante nuestra investigación.

2 La noción de fundamento va a ser harto importante en el pensamiento posterior a la llamada Kehre del propio Heidegger (1976, pp. 175-199). Aquí es empleado como acción de "fundar" [gründen], es decir, en tanto "instaurar" [stiften], "tomar-suelo" [Bodennehmen] y acto de "fundamentar" [Begründen]. En este sentido, la verdad del ser, podríamos decir, acontece solo a través del existir del Dasein, quien instaura, toma suelo y fundamenta la verdad. Por esta razón, el Dasein es un fenómeno fundamental. Para su contraposición con la teoría de la verdad expuesta post Kehre, nos permitimos citar: Garrido-Periñán, 2016, pp. 203-216.

3 Nos valemos del término empleado por A. Vigo, quien a su vez lo toma de Gadamer (1993, pp. 177 ss.). Para Vigo, la aleteiología es un intento por reubicar la temática de la verdad, entendida como aletheia, dentro de lo que, por la tradición, se denominó "verdad trascendental", esto es, como la apertura que permite la comprensión del ente en su ser. 
pondría al Dasein ante la verdad del (su) ser, precisamente, en la posibilidad proyectada en tanto "estado de apertura" [Erschlossenheit], donde tal poderser, que es el Dasein, se abre para sí mismo. ${ }^{4}$ Nótese, por tanto, que hay una mención que conecta al Dasein con la verdad y su "mismidad"5 [Selbstheit]. Al menos, por el momento, esta mismidad tan solo quiere manifestar una modalidad por la que el Dasein, estando en la verdad, se abre para sí mismo. En tal apertura de/ante sí radicaría el fenómeno de ser sí-mismo.

Como es bien sabido, y como se echa de ver en la II Sección, la concretización fenomenológica de la mismidad del Dasein es recogida, principalmente, por el fenómeno del "llamado de la conciencia" [der Ruf des Gewissens] (SuZ, pp. 231-333). Ahora bien, tal forma de desarrollo temático no será pensada en esta meditación; antes al contrario, buscamos tematizar la mismidad del Dasein dentro de los límites intrínsecos del $\S 44$, en plena conexión con el existenciario verdad de la existencia, a fin de entender la mismidad como un fenómeno eminente, y ontológico, de libertad ${ }^{6}$. Tal derivación hacia la libertad tendrá que mostrar que la conexión Dasein-verdad solo se puede llevar a término al socaire de un desarrollo de la mismidad del ente Dasein entendida esta como un fenómeno relativo al "poner/quedar en libertad" [freigeben/Freigabe] y al "ser-libre" [Freisein]. Este será, en último término, el objetivo de nuestra investigación.

\section{La libertad en SuZ: el dejar/quedar en libertad y el ser-libre del Dasein}

Heidegger cree encontrar "el fenómeno más originario de la verdad" [das ursprünglichste Phänomen der Wahrheit] en el "estado de abierto"

4 Hablando sobre la verdad de la existencia, Heidegger manifiesta: "La última posibilidad alude a que el Dasein se abre para sí mismo en y como el más propio poder-ser" [Die letztgenannte Möglichkeit besagt: das Dasein erschließt sich ihm selbst im eigensten und als eigenstes Seinkönnen] (SuZ, p.221). El autor del texto asumirá las traducciones de la obra de Heidegger.

5 De modo muy provisorio, el sí-mismo, o la mismidad, apunta a un fenómeno temporal en las dimensiones prácticas del "mundo entorno" [Um-welt], "mundo compartido" [Mit-welt] y, por último, "mundo de sí mismo" [Selbst-welt] (Heidegger, 2006, pp. 176; 1995, pp. 11, 13, 103, 187-188, 192, 204, 211, 212- 214, 227-228, 232, 237-241, 245-247, 253-255, 298, 331-332; 1992, pp. 54-58, 342, 348, 440-441; 1988, pp. 29 y 102 ; 1976 , pp. 236, 338-344-347; 1975, pp. 194, 224-228, 242, 249, 394-395, 422, 425).

6 Sería conveniente precisar que nos abstenemos de un desarrollo temático de las obras heideggerianas que van de la segunda mitad del año 1927 a 1931, justamente donde, de una manera más evidente, se desarrolla la temática de la libertad. De forma muy resumida, en aquellos escritos, Heidegger intenta elaborar la temática de la "libertad" [Freiheit] (Figal, 1991; Schmidt, 2015) en términos de "transcendencia" [Transzendenz] del Dasein, en un intento, casi frenético, de librar a su propio pensar de los caracteres que definen el contorno de un pensar metafísico. De ahí que la gesta de llevar a cabo una "superación de la metafísica" [Überwindung der Metaphysik] no se pudiera ejercer desde la misma metafísica. Por último, durante este intervalo temporal, la figura de Kant gana protagonismo, por cuanto la transcendencia del Dasein, mutatis mutandis, significa llevar a cabo la posibilidad de un transcender finito, que Heidegger creyó encontrar en el pensamiento de Kant (Vigo, 2010, pp. 297-334). 
[Erschlossenheit], que surca al ser del Dasein, en la medida en que este ente vive en un estado de "cuestionabilidad" [Fraglichkeit] radical, tensado, formal y existencialmente por las modalidades del "tener-que-ser" [zu-sein] y el"seren-cada-caso-mío" [Jemeinigkeit] (SuZ, pp. 42-45). Por tanto, más allá del hegemónico desarrollo de la verdad como adaequatio, la verdad originaria es el fundamento que permite que el ente intramundano sea "descubierto" [Entdecktheit] bajo la modalidad relativa al "ser-descubridor" [Entdeckendsein], específica del Dasein. El acto, por así decir, del "estado de descubierto" [Entdecktheit], se ejerce según los modos de acceso al ente intramundano, ora en tanto relativo al "mundo-entorno" [Umwelt], es decir, "a la mano" [zuhanden], ora en relación con el comportamiento teorético y/o mundo teorético, o sea, como "ante los ojos" [vorhanden]. En ambos modos de acceder al ente, tal ente deviene descubierto. Pero, nota bene, no hay ser-descubierto que no presuponga, para ser, un "estado de abierto" [Erschlossenheit], que porta el Dasein en cada caso. En virtud de esta dependencia de los entes intramundanos hacia el modo de ser del Dasein - el encargado de abrir, sea el caso, los determinados respectos del ser-descubierto -, pensamos que se podría hablar de libertad, a pesar de que, como se manifestaba en el punto anterior, en las líneas que cubren el $\S 44$ de $S u Z$, Heidegger ni siquiera mencione la palabra libertad como tal para hacer referencia a la situación del Dasein en tanto ente sumamente abierto, constituido por el estado de apertura. ¿Cómo es posible hablar de libertad en este punto? ¿ Es posible que el estado de abierto del Dasein pueda ser desarrollado y llevado a cabo como libertad sin contar con las obras posteriores a SuZ? ¿Se puede, por ende, hablar de libertad en el tratamiento que hace Heidegger al estado de abierto?

Estas cuestiones son intrínsecamente arduas, pues no aparecen explicitas en el opus magnum heideggeriano. De suerte que, hasta lo desarrollado en el $\S$ 44, sí que se pueda, al menos, intuir, aunque sea implícitamente, un desarrollo en términos de libertad de tal estado de abierto propio del Dasein, a saber: a) en el desarrollo temático del "útil" [Zeug] (SuZ, pp. 83-89), éste queda caracterizado, en relación al "contexto-respeccional"7 [Bewandtnisganzheit], como un "dejar/poner en libertad" [freigeben/Freigabe] al ente intramundano

7 Hacemos mención al carácter de la "mundaneidad" [Weltlichkeit] y a la explicación que da el propio Heidegger sobre el aparecer de los útiles y el mundo entorno. El "contexto pragmático", el cual comporta el mundoentorno, queda emparentado con el ámbito que soporta el "para-algo" [Um-zu] de la remisión del útil, mientras la "totalidad respeccional" es un fenómeno ligado al "por-mor-del" [Worum-willen] Dasein, o sea, al ámbito de auto-remisión que todo útil, en tanto para-algo, comporta. El existenciario del cual es deudor la "totalidad respeccional" es el "todo respeccional" [Bezugsganze], que vendría a actuar de elemento trascendental, por cuanto contendría la totalidad de "condiciones respectivas" [Bewandtnisganzheit] como su (auto)referencia hacia el Dasein - la significatividad y mundaneidad -. 
en su peculiar significatividad; b) y, a la par, en la medida en que el fenómeno de la "conformidad" [Bewandtnis], a fin de ser comprendido, remite a un fenómeno de anticipación del propio Dasein, por cuanto el "por-mor-de" [Worum-willen] constitutivo de tal Dasein queda determinado como un "ser-libre" [Freisein] para ser lo que es. Por tales motivos, pensamos que es posible realizar un desarrollo temático de la concepción libertad desde $S u Z$, en concreto desde el $\S 44$. Toca, ahora, desarrollar los aspectos “a)" y "b)".

1.1 El dejar/poner en libertad el ente intramundano: el rescate de la vinculabilidad

La noción de conformidad, desarrollada en el § 18, se ha de entender como un trasunto fenomenológico-hermenéutico, por la que la impronta existencial y específica del Dasein sale a relucir en tanto condición de posibilidad para que el útil, que es aquello de lo que nos valemos en la "ocupación" [Besorgen], pueda ser comprendido, o sea, adquiera significación. En este sentido, grosso modo, Heidegger manifestó que, en el uso y/o trato que le damos a los útiles, por medio y a través del cual nos valemos en el mundo, gobierna siempre ya una conformidad, holística y articuladora, la cual, además de dotar de significación al mismo ente-útil, lo concretiza en su posibilidad fáctica (Garrido-Periñán, 2019a, pp. 175-200). Este hecho de "concreción óntica" [ontische zunächst], muchas veces pasado por alto a favor de desarrollos ulteriores sobre el fenómeno de la "significatividad" [Bedeutsamkeit], es extremadamente importante, pues concreción significa "vinculación" [Verbindung], o mejor: posibilidad de que el ente intramundano, en su concreción de útil, pueda ser remitido al agente de experiencia y/o de uso, esto es, al Dasein. Justamente, un ente deviene concreto, si y solo si, al ser inscrito dentro de un horizonte proyectivo, de anticipación, que soporta el Dasein por cuanto es un ente trenzado por el "cuidado"8 [Sorge], se lo comprende como posibilidad que, de alguna manera, está vinculada con nuestro modo de ser, la existencia. La inscripción en una posibilidad, por parte del útil, que es siempre "a la mano" [zuhanden], se ejerce dentro del dominio pre-ontológico del ser del Dasein, donde este ente, siendo "no-extraño" [nichtFremd] (SuZ, p. 16), permite que el útil devenga como en su ser. Por esta razón, el existenciario "conformidad" [Bewandtnis] es tan importante, ya que permite que el útil mantenga un vínculo con el Dasein, haciendo posible, de este modo, que éste tenga algo así como un "ser". En este sentido, a fin de mentar

8 El nexo entre anticipación y cuidado queda claro en la misma definición del existenciario cuidado:“El cuidado es el título ontológico para la totalidad del todo estructural del Dasein". [Sorge ist der ontologische Titel für die Ganzheit des Strukturganzen des Daseins] (SuZ, p. 252). 
la relevancia de la pre-comprensión anticipativa del útil en su conformidad a través de un respectus, Heidegger versa sobre una "previa puesta en libertad"9 [vorgängige Freigabe]. El útil, entonces, queda puesto como en libertad en la medida en que se articula en una posibilidad que sostiene el Dasein en su "estado de arrojado" [Geworfenheit]. La posibilidad ha de significar, en este sentido, la constatación de la "vinculabilidad" [Verbindlichkeit] entre útil y Dasein, de tal forma que, como es usual en Heidegger cuando habla del "cómo" [Wie] fenomenológico, se pueda sostener que los modos de acceso desembocan siempre en lo que "es", en la cosa misma: el ente siempre ha de aparecer en una modalidad de acceso.

Ahora bien, el fenómeno de tal puesta en libertad, o dejar en libertad el útil en su plexo de conformidad, no es el resultado de una acción, sea práctica o teórica, del Dasein, como a voluntad, sino que, antes bien, acontece siempre ya, en un "haber dejado siempre ya conformarse" [je-schon-haben-bewendenlassen] propio de la facticidad. De esta forma, tal libertad queda caracterizada como la posibilidad de que, en este caso, el ente-útil se pueda conformar, en la modalidad intencional del "ser a la mano" [Zuhandenheit], dentro del contexto englobador y holístico del circum o Um- del mundo. La plena adecuación noapofántica (Garrido-Periñán, 2019b, pp. 887-911; Vigo, 2014b, pp. 437-466), llamada también aquí vinculación, entre el modo ocupacional de lo "a la mano" y el mundo-entorno, característica de la puesta en libertad del útil, es posible porque el Dasein "deja-conformarse" [bewenden-lassen] a tal vínculo, siendo que aquello que es "a la mano" ya siempre ha quedado remitido a un mundo, en tanto plexo respeccional y/o de conformidad relativo a la "mundaneidad" [Weltlichkeit]. El Dasein es, por tanto, responsable de tal puesta en libertad, pues deja al ente-útil venir a presencia en su conformidad.

Por otro lado, este análisis, relativo al fenómeno llamado freigeben/ Freigabe, no tiene, tan solo, un carácter explicativo, por así decir, en relación con la génesis del útil, sino que constituye una "determinación ontológicacategorial" 10 [ontologische-Kategoriale Bestimmung] (SuZ, p. 71) encargada de determinar el ser específico del ente intramundano. Por más que miremos

9 En este sentido, Heidegger dice al respecto: "El análisis, hasta ahora, ha mostrado que el ser de lo que comparece dentro del mundo deja/queda en libertad para la circunspección ocupada que soporta aquel ente" [Die bisherige Analyse zeigte: das innerweltlich Begegnende ist für die besorgende Umsicht, das Rechnungtragen, in seinem Sein freigegeben] (SuZ, p. 83).

10 Recomiendo la lectura de Dos Reis (2018, pp. 121-142), donde, de una manera magistral, explicita, desde la perpectiva de Heidegger, la cuestión genética sobre el origen del conocimiento científico, en tanto modo teorético de proceder y, por ende, dando cuenta del tratamiento derivativo por el que Heidegger cree circunscribir el conocimiento científico, como fenómeno deudor y parasitario de una articulación de carácter preteorético o antepredicativa, la cual funda todo tipo de proposición enunciativa, proposicional o judicativa. 
alrededor y teoricemos, Heidegger está empeñado en caracterizar la modalidad del ser-a-la-mano, por la cual se gesta el dejar/quedar en libertad, como condición de posibilidad de cualquier determinación ontológica del ente intramundano, incluso aquella posibilidad propia del comportamiento teorético de la que hace mención las ciencias positivas, a saber, la física, la biología o la psicología, entre otras. Esto tiene unas consecuencias importantísimas en conexión con la "teoría del conocimiento" [Erkenntnistheorie] y, más aún, ante la pregunta sobre la génesis del conocimiento científico, que exceden, sin lugar a duda, el núcleo temático de nuestra investigación. Empero es importante hacer notar lo siguiente, sobre todo en la posible función que ejerce la signatura del dejar/ quedar en libertad en todo esto: la afirmación de que el ser-a-la-mano constituye la determinación ontológico-categorial del ente intramundano implica que tal ente, dado en el modo de acceso de "ser ante los ojos" [Vorhandensein], el ente proveniente del "conocer teorético" [Erkennen], no puede más que aparecer como un ente producto de una fuerte modificación reductiva, en donde la conformidad, que fue enfatizada y potenciada en la modalidad de lo "a la mano", se ve como nivelada y obstruida, de tal manera que lo que se pierde, a través del proceder teorético, es la libertad de la misma puesta en libertad del ente en-su-mundo, es decir, en su plexo total de conformidad ( $S u Z$, p. 88). El conocimiento teorético sería, entonces, la abolición del dejar/quedar en libertad para con el ente intramundano. Solo así es posible que Heidegger, sin apelar a motivaciones humanísticas, hable de la "desmundanización del mundo" [Entweltlichung der Welt] (SuZ, pp. 65, 75, 112 y 113), pues la desmundanización del mundo ha de significar la pérdida de la posibilidad de quedar en libertad del ente intramundano en su mundo, en tanto obturación y erradicación de toda posible forma de "vinculabilidad".

Cuando se ha omitido el vínculo "ente-intramundano y Dasein", el horizonte llamado mundo adquiere los rasgos de la "uniformidad" [Einformigkeit] (SuZ, pp. 134-141), donde, a través de un "dirigir la mirada de carácter teorético" [theoretische Hinsehen], el ente intramundano aparece como algo que está-ahí, en el sentido de la Vorhandenheit. Tal ente viene a presencia siempre igual, uniformemente, sin necesidad de una experiencia que lo abra reclamándolo desde su origen. De suerte que el dejar/quedar en libertad [Freigabe/freigeben], en su tendencia contraria a la uniformidad, descubre todo vínculo perteneciente al ente intramundano con el agente de experiencia, el Dasein. Tal vínculo es, por tanto, el "espacio" donde acontece "lo abierto"11 [das Offene], siendo que 
lo que se lleva a término en el dejar/poner en libertad es el ente en lo abierto como mundo. Solo así es posible su aprehensión más originaria.

\section{El ser-libre del Dasein: prolegómenos para un desarrollo de la mismidad}

Prima facie, la afirmación de que el Dasein es libre para su propio poderser, tiene que ser tomada con toda cautela. Por el momento, el existenciario que vamos a pensar, el "ser-libre" [Freisein], ha de ser concebido como modalidad distinta al modo de ser perteneciente al ente intramundano: el Dasein es un ser que "le va su ser en ser (existir)" [es geht ihm um sein Sein]. Esta afirmación, muy del gusto de Heidegger, la vamos a emplear aquí para poner en alza la tendencia trascendental, en el sentido de ir "más allá", peculiar del este ente llamado Dasein, por la cual, este ente, siempre se dirige al ente en su ser, preguntando, buscando, en definitiva, existiendo. Del mismo modo, toda tendencia de ir "más allá" del ente, conlleva una retorsión, una "(vuelta)-hacia" [zum], de tal guisa que, yendo más allá, este Dasein vuelve sobre sí, "haciéndose-cargo" [Übernahme], sea como sea, de aquello que el ente "es", desde una posibilidad ejecutivo-comprensiva que es él mismo. Con estas, podríamos manifestar, aunque de modo todavía hipotético, que el ser-libre del Dasein constituye la condición de posibilidad para que acontezca, de algún modo, el dejar/quedar libre del ente intramundano, siendo que el ser-libre, idiosincrático del Dasein, constituiría "el primario para-qué" [das primäre Wozu], esto es, la condición fundante que permite a los determinados "para", siempre con relación a un respecto de conformidad, ser articulados, proyectiva y comprensivamente en una posibilidad fáctica de ser. El ser-libre del Dasein insertaría, entonces, en los diversos "para", al que se ven relacionados los entes intramundanos, su posibilidad comprensiva, o lo que es lo mismo: tatuaría en los diversos "paraqué" $[U m-z u / W o z u]$ la propia facticidad, por la cual aquello que es puede ser vinculado con el Dasein, como yéndole de alguna manera. ${ }^{12}$ En este sentido, es sumamente curioso que, en el desarrollo del estado de abierto del $\S 44$, donde tiene lugar la tematización tan importante para la ontología de la cuestión de la verdad (aletheia), Heidegger, sin titubeos, va a distinguir el estado de abierto como un "estado de arrojado" [Geworfenheit] (SuZ, p.221), permitiendo así emparentar la cuestión de la verdad del ser con la verdad del Dasein, o lo que es igual: la "verdad de la existencia" [Wahrheit der Existenz]. Esto, además, 
tiene unas consecuencias metodológicas notorias, por cuanto la homologación entre verdad y estado de abierto del Dasein, siendo siempre ya un estado abierto que es fácticamente arrojado, permite situar la pregunta por la verdad en el terreno de lo que está ya determinado, ora por el entorno, ora por los otros, ora por la historia. Esta forma de comenzar, que la fenomenología debe considerar en su aspiración de aprehender cómo el ente es dado en la experiencia, es llamado por Heidegger con la expresión "cotidianidad del término medio" [durchschnittliche Alltäglichkeit]. Su valía, en el contexto metódico, estriba en situar la cuestión de la verdad siempre en una posibilidad, que queda vinculada en una concreción fáctica, no habiendo, entonces, un estado de abierto como "flotante en el vacío" [freischwebende] (SuZ, p. 279), sino que toda verdad, en tanto estando abierta, es una verdad determinada desde el mundo, los otros, o desde el más propio poder ser del Dasein. Es digno de advertir, también, de qué modo la temática de la "propiedad" [Eigentlichkeit], tan importante en los devenires de la II Sección (SuZ, pp.231-437), está ya implícitamente supuesta en la noción de verdad desarrollada en el § 44. Precisamente, en virtud de la homologación que parece existir entre verdad-Dasein, el modo propio, o sea el fenómeno de la verdad más originario, es la "verdad de la existencia" [Wahrheit der Existenz], entendida como acción proyectivo-ejecutiva que, "desde el modo de la propiedad" [im Modus der Eigentlichkeit], coloca al Dasein ante su más genuino poder ser (SuZ,p. 221).

Todo parece indicar, empero, que la noción de ser-libre ha de ser conectada con la otra de verdad de la existencia. En tal nexo, entonces, se debe desarrollar una explicitación de la propiedad del Dasein, la cual ha quedado ya implícita en la misma noción de ser-libre. Se trataría, pues, a partir de ahora, de indagar en qué medida la noción de ser-libre necesitaría de un desarrollo más explícito sobre la mismidad del Dasein, justamente en la medida en que se postula tal mismidad como un fenómeno eminente por el que, y a través del cual, el Dasein se abre para sí mismo lo que es: una posibilidad proyectivo-ejecutiva siempre ya fácticamente dispuesta.

2.1 El ser-libre y mismidad: el horizonte de la medianía y la pérdida de sí

La intención de situar la cuestión del ser-libre en los términos relativos a la verdad de la existencia es muy clara: ser-libre ha de significar "ser libre para el propio poder ser" [Freisein für des eigensten Seinkönnen]. A resultas de esto, si es cierto que hay una interdependencia entre verdad-Dasein, por 
cuanto la verdad del ser es la verdad que sostiene el Dasein en su "ahí"13 [Da], tenemos que aceptar que no hay ser-libre si antes no ha acontecido el dejar/ poner en libertad del ente intramundano. El Dasein no puede ser libre para su propio poder ser si queda como desvinculado de los momentos estructurales que componen lo que es él mismo: un ser-en-el-mundo, esto es, una modalidad intencional desde el "mundo-entorno" [Umwelt], el "mundo-compartido" [Mitwelt] y el "mundo de sí mismo" [Selbstwelt]. Estos ámbitos, en rigor, no han de ser entendidos como estancos y separados, como si el Dasein, a veces, fuera en el mundo compartido, otras en el mundo de los útiles. No. Más bien, la caracterización del Dasein como "ser-en-el-mundo" [in-der-Welt-sein] busca situar la temática de la mismidad como una "manera de existir" [Weise zur existieren], desvinculándola de posibles tendencias reificadoras propias de la Vorhandenheit, y, a su vez, en la medida en que la verdad del ser solo se ejerce desde la verdad de la existencia referida al Dasein, esto significa que ésta ha de buscarse en los fenómenos de concretización óntica de este ente señalado llamado Dasein. Ante esta cuestión, Heidegger ya ha lanzado una pregunta dentro de su extensa analítica existencial: ¿quién es el Dasein? y ha dado una respuesta muy clara: el "uno-mismo" [man-selbst] (SuZ, p. 271), esto es, una modalidad de ser auto-delegatoria y nivelada, a través de la cual este ente elude su más propia posibilidad de ser: el "ser-para-(vuelto-a)-la-muerte"14 [seim-zum-Tode].

Ubicar, entonces, el tópico de la verdad en términos de ser-libre nos ha llevado a la necesidad de pensar sobre el modo a través del cual el Dasein es lo que es en su medianía. Desde este punto, se patentiza que el Dasein vive en el modo nivelador de la "perdida de sí" [Selbstverlorenheit], dentro del impersonal uno, donde el estado de abierto aparece como "desfigurado" [entstellt] en su impronta existencial. Ahora bien, semejante afirmación no hace más que manifestar la necesaria imbricación que el ser-libre tiene para con la propia constitución del Dasein como posibilidad de ejecutar existencial y comprensivamente la verdad de la existencia: él es siempre ya su ser-libre. El hecho fáctico de que este Dasein, en el modo del uno, se cierre en sí y huya de su más eminente posibilidad, no hace más que presuponer que, siempre ya, está abierto en su ser.

13 De este modo, lo expresa Heidegger: "Hay verdad solo siempre que, y mientras, el Dasein es". [Wahrheit gibt es nur, sofern und solange Dasein ist] (SuZ, p. 226).

14 Nos abstenemos de desarrollar con más demora tal temática, a pesar de que constituye el núcleo de la posibilidad de que el Dasein, llegado el caso, puede aprehender, de manera total [Ganzheit], su propio poderser mediante el "llamado de la conciencia" y la culpa [Schuld]. Nos permitimos remitir, a fin de que el lector pueda ampliar esta fascinante temática, a la siguiente publicación: Garrido-Periñán, 2017, pp. 159-182. 


\subsection{El ser-libre y la elección: desde la opacidad a la transparencia}

El establecimiento de la libertad y/o ser-libre, en términos de "pérdida de s'́" [Selbstverlorenheit], por cuanto el Dasein es regularmente el uno-mismo, sitúa el problema de la libertad dentro del contexto de la pregunta por el símismo de tal ente. En este sentido, la experiencia de la libertad radical, el ser-libre para el más propio poder ser, ${ }^{15}$ ha de constituir el fundamento que dé cuenta de la inercia cinética, sumida en el "estado de caída" [Verfallen], en la que el existente se ve inmerso en su día a día. Aunque, bien es verdad que, en el análisis fenomenológico de descripción y en primer lugar, nos topemos con esta forma nivelada y auto-delegatoria del uno, desde otro modo, en cambio, podríamos decir que el fenómeno de la pérdida de sí es deudor con respecto al ser-libre, en el sentido genuino de que este ser-libre es un fenómeno emanado del estado de abierto que el Dasein siempre es, por cuanto está caracterizado por el tener-que-ser y el ser-en-cada-caso-mío. El hecho de que la perdida de sí sea una posibilidad de "sí", y no de otra cosa, es posible solo porque el Dasein, en cada caso, permanece abierto ante su más específica y singular posibilidad: constituirse como un poder-ser en un horizonte temporal finito, un poder-ser que es asumido, sea como fuere.

Pues bien, este marco referencial nos hace situar la libertad, en relación con el fenómeno de la pérdida de sí, en el contexto de la "elección" [Wahl]. Tal elección, como es de suponer, no ha de entenderse al modo de la libertad negativa, ni tan siquiera como la libre voluntad de un individuo de elegir y optar por algo, sino como una posibilidad, comprensivo-ejecutiva y fáctica, a través de la cual el Dasein puede "recuperar una elección" [Nachholen einer Wahl] (SuZ, pp.267 ss.), de abrirse para sí-mismo. Se puede decir de otro modo: el modo eminente de libertad denominado recuperar la elección es la única vía en la que el Dasein puede existir en concordancia con su estado de abierto. Todas las formas de huida, negación y/o "cerramiento" [Verschlossenheit] son maneras que obstruyen tal estado de apertura, singular de la existencia. Ahora, por cierto, es posible ver el vínculo establecido al principio de la investigación

15 Como se viene diciendo, la constatación más plena, en relación con este ser-libre para el más propio poderser, adviene a través del existenciario "ser-para-(vuelto-a)-la-muerte" bajo la siguiente signatura "libertad para la muerte" [Freiheit zum Tode] (SuZ, p. 266), pero, no obstante, este ser-libre ha sido ya, antes, mencionado por Heidegger. En primer lugar, cuando se despliega el análisis del "comprender" [Verstehen], tal poder ser libre queda caracterizado como una posibilidad, aunque afectivamente dispuesta, siempre referida a una situación fáctica y concreta por la que el Dasein debe hacerse cargo y/o responsable (SuZ, p.144); en segundo lugar, en el análisis del cuidado, tal ser-libre queda prefigurado en el momento del "proyecto-anticipativo" [sich-vorweg-schon-sein Entwurf], singular del modo de ser del Dasein (SuZ, p. 193). En cambio, en el $\S 44$ analizado en la presente investigación, este ser-libre para el propio poder-ser será articulado mediante el estado de abierto por el cual el Dasein es eminentemente ontológico. De ahí su importancia. 
entre verdad de la existencia y estado de abierto: la verdad de la existencia es un correlato existencial del ser-libre en tanto elegir una elección.

Siguiendo este hilo conductor, Heidegger parece indicar que los resultados de tal decisión, tomada en propiedad, derivan en una teoría del conocimiento existencial del Dasein mismo. A esta forma de conocimiento y saber de sí por parte del Dasein, en contraposición de las derivas de la llamada "teoría del conocimiento" [Erkennistheorie], fue llamada con el rótulo de "transparencia" [Durchsichtkeit] (SuZ, p. 146). La transparencia, no obstante, desde el principio, es descartada como forma de conocimiento teorético, del que se pudieran derivar, dentro de sus definiciones, "propiedades" [Eigenschaften]; más bien, la transparencia es un modo ejecutivo de comprensión, naciente del Dasein, por el que este ente es capaz de responsabilizarse de su estado de abierto, en tanto ser-en-el-mundo como un todo, esto es, abriéndose radicalmente por cada uno de los momentos estructurales: el mundo-entorno, mundo compartido y el mundo de sí-mismo. En tal estado de transparencia, que es un estado de ejecución comprensiva y temporal, en cada caso, el Dasein se "avista" [sichtet] de una manera holística, entendiendo así su propio ser en tanto ser-en-elmundo. Por tanto, desde tal transparencia, el Dasein puede comprenderse desde sus respectivos correlatos existenciales: el "ser-junto-a" [sein-bei] y, también, desde el "ser-uno-con-otros" [Mitsein mit Anderen]. Nótese de qué manera, al igual que sucedía con el fenómeno de la pérdida de sí, la transparencia tiene su opositor: la "opacidad" [Undurchsichtigkeit] (SuZ, p. 146), entendida como un fenómeno de auto-engaño y nivelación por el que este ente, no solo se desconoce a sí mismo, sino por el que es incapaz de dar cuenta de su relación con el mundo y con los otros (SuZ, p. 146). Como se echa de ver, esta coincidencia en sus opositores no es solamente superficial; antes bien, constituye una consecuencia por la que el Dasein, siendo su estado de abierto, siempre ya oscila entre modalidades de propiedad y/o impropiedad, cuando no de indiferencia ${ }^{16}$. Lo importante es, quizás, que se ha mostrado una vía para pensar la mismidad del Dasein: mismidad ha de significar capacidad de transparencia, y esta transparencia queda constituida por todos los momentos estructurales del ser-en-el-mundo.

16 Muy interesante es la mención de la modalidad de concreción existencial denominada "indiferencia" [modale Indifferenz] (SuZ, pp. 232 ss.). Por diversos motivos, tanto de forma como de contenido, no abstenemos de desarrollar una interpretación de tal modo de ser basado en la indiferencia, a fin de centrarnos en el binomio impropiedad-propiedad. Valga esta indicación como suficiente: la indiferencia modal sería un modo derivado de la impropiedad, no de la propiedad, porque, en todo caso, un Dasein indiferente es aquel que ve socavado y obturado un momento estructural de su apertura: la "disposición afectiva" [Befindlichkeit]. 
Es hora, pues, de que el análisis del modo de aparecer de los otros busque fijar el horizonte de la mismidad del Dasein, en relación con el concepto de libertad entendido como ser-libre.

\subsection{El ser-libre y la mismidad: la necesaria co-implicación de los otros}

Algo antes del $\S 44$, en los $\S \S 25-27$ (SuZ, pp. 114-130), Heidegger se ha ocupado de analizar la cuestión sobre cómo aparecen los otros, que son Dasein, al igual que nosotros (yo y tú). Obviamente, su concepción dista de ser dialógica, o de tomar la alteridad como fundamento a fin de comprender al Dasein en y sobre el otro como otro, en tanto alteridad o rostro (Bernasconi, 1988; Levinas, 1999, pp. 201-261; Theunissen, 1977). En la obra SuZ, por necesidad metódica, el aparecer de los otros tiene que acontecer circundado por lo retenido hasta el momento en los análisis del mundo-entorno. En algún sentido, nimio y algo tímido, la prefiguración de los otros se ha de sentir en el modo de aparecer de los útiles, por cuanto éstos quedan, en su constitución, auto-referenciados por un modo de anticiparse a sí del Dasein denominado "por-mor-de" [Worum-willen], o lo que es lo mismo, pero dicho de manera más plástica: los otros están ya contenidos en la experiencia de útil en tanto portadores, usuarios, clientes, etc. Se puede pensar, empero, que la forma de análisis heideggeriano es brusca e insensible, pues parece homologar el modo de aparecer de las cosas-útiles a su modo de comparecencia, a saber, se podría poner en igualdad el aparecer de un martillo con el de nuestro amigo o pareja ¿Realmente Heidegger está afirmando semejante descripción fenomenológica? En nuestra opinión hay que andar con mucho tiento, el análisis ontológico-existencial que Heidegger está ejecutando en $\mathrm{SuZ}$ ha de respetar unos compromisos metódicos que, simultáneamente, se conectan con contenidos significativos y conceptuales muy importantes para comprender lo que se trata en la obra. Para resumir la hipótesis principal de partida del análisis del ser-en-el-mundo, Heidegger piensa que el Dasein, antes de nada, es lo que se ocupa. ${ }^{17}$ Esto quiere decir que, in nuce, estamos imposibilitados, a fin de pensarnos a nosotros mismos como substancias y/o género, al modo de los "auto engaños egocéntricos" [egozentrische Selbsttäuschungen], sobre todo si queremos captar, al modo fenomenológico, o sea sin teorizaciones, la manera peculiar de aparecer de nuestra existencia, y en particular, de los otros que son Dasein. Este compromiso comporta, pues, a fin de pensar el modo de comparecencia de los otros, partir del modo de aparecer de los útiles, ya que 
los otros aparecen no desligados del contexto hermenéutico llamado mundo, sino "dentro-de/junto-a" [bei] al mundo. Tal formalidad, de corte metodológico, viene acompañado de un contenido conceptual: el otro posee, a grandes rasgos, y prima facie, el carácter del ente-intramundano. Nota bene, Heidegger ha llegado a la siguiente afirmación a causa de las consecuencias adoptadas por la continencia fenomenológica de atenerse a las cosas mismas, mas no por haber idealizado ingenuamente, sin atestiguación, el carácter que le correspondería a los otros en tanto "dados" en la experiencia.

Por otro lado, es de justicia destacar una ambigüedad que recorre la interpretación de Heidegger sobre los otros, ya que, pronto en el recorrido de su analítica, éste se da cuenta de que otro-Dasein no puede ser abrazado por el carácter de la "reemplazibilidad" [Ersetzbarkeit] (SuZ, pp.117-125). Mientras el cuchillo, por más antiguo que fuera, se rompe y puede ser sustituido por otro cuchillo, los otros-Dasein, en su muerte y ausencia, son, por esencia, irreemplazables e "irreferibles" [unbezüglichen]. En este sentido, Heidegger ya distingue un rasgo peculiar del modo de aparecer de los otros. En esta distinción, que potencia su peculiar mostración, el otro-Dasein, el cual aparece dentro del mundo, también aparece teniendo mundo, soportándolo, preguntándose sobre su propia existencia. Esta sutil distinción es muy importante, pues significa, en términos del propio análisis existencial, que el otro-Dasein está atravesado por los existenciarios que preservan la existencialidad y la facticidad: el tener-que-ser y el ser-en-cada-caso-mío. Solo de este modo se puede explicar una estructura existencial y ontológica llamada "ser-con" [Mitsein], en tanto estructura que posibilita, configurándola, toda posible acción de comunicación, de co-existencia y/o "coexistir" [Mitdasein] (SuZ, p. 117-130). El prefijo existencial Mit-, el cual siempre implica la presencia del otro o de los otros en el Dasein, no es aséptico, ni abstracto, en el análisis que Heidegger está llevando a cabo, pues la esfera del otro, englobada en el Mit- de carácter ontológico, significa: a) que el otro es "también ahí con" [auch und mit da]; b) que, tal "con" [Mit-] no tiene la forma propia de la Vorhandenheit, sino de la existencia; c) y, por último, "el también" [das Auch], en relación al estar ahí del otro, significa que el Dasein es desde siempre en un mundo-compartido. A través de esta tripartita definición, en nuestra opinión, se está aceptando una "igualdad de ser" [Gleichheit des Seins], en donde se aprecia que el comportamiento práctico del "ver en torno" [Umsicht], respectivo del ser-en-el-mundo, se da siempre ya en un mundo-compartido. El "ser-en" [In-Sein], que guía la movilidad intencional del Dasein, lo que este ente "es", se da ya en un mundo compartido, con los otros, y desde la base de un "ser en sí intramundano" [innerweltliche Ansichsein] que, es, per se, compartido, para todo Dasein por igual. 
La singularización del modo de comparecencia de los otros es realzada por el mismo Heidegger cuando versa sobre la "solicitud" [Fürsorge] (SuZ, p. 121). La solicitud es una estructura de carácter fundante con respecto a todo trato concreto e individual en relación con los otros, no una figura normativa y moral que dictara cómo debe el Dasein comportarse en cada caso. Lo importante es que hay una diferenciación entre el carácter de ser de los útiles, llamada "ocupación" [Besorgen] y el carácter de ser relativo a los otros, denominada "solicitud" [Fürsorge]. Si seguimos el compromiso fenomenológico establecido por Heidegger - los modos de acceso determinan lo que es la cosa-, podemos afirmar que, entonces, el modo de acceso de los útiles no es suficiente a fin de aprehender el modo de ser singular de los otros. Por tanto, para resumir, los otros nunca pueden ser homologados a los útiles, por más que, de algún modo, su darse acontezca dentro del mundo.

Toca, pues, fijar nuestra atención en el existenciario solicitud. Una vez realizada la advertencia hacia posibles interpretaciones de carácter moral, alejadas de lo que Heidegger quiere manifestar, es notable hacer notar que, al igual que sucede con el ser-libre del Dasein, la solicitud está marcada por las posibilidades existenciales de la impropiedad, la propiedad y la indiferencia. En referencia a los intereses de nuestra meditación, a fin de potenciar el momento puntual del ser-libre, dejaremos como al margen las consideraciones que hace Heidegger sobre los modos de solicitud impropia e indiferente (Garrido-Periñán, 2019a, pp. 175-200). Pues bien, la solicitud, la cual es una estructura que constituye la condición de posibilidad de todo acto con los otros, cuando se da propiamente, esto es, cuando deviene autorreferencial, permitiendo la apertura del Dasein en sí-mismo, viene rasgada por un carácter "anticipativo-liberador" [vorsprunggend-befreend], el cual tiene lugar como un acto ligado a la misma anticipación existencial del Dasein, en tanto tener-que-ser y ser-en-cada-casomío. Aquello que anticipa el Dasein en la solicitud liberadora es como un "salto anticipativo frente al otro" [Vorausspringen dem Anderen gegenüber] bajo la finalidad ineluctable de devolverle al otro lo que está siempre ya a su cuidado como lo que, justamente, está a su cuidado, sin más. Quizás se puede decir de forma más resumida y clara: la solicitud anticipativa-liberadora, lo que busca es que, mediante el ser-uno-con-otros en la co-existencia diaria, cada existente puede hacerse cargo de su existencia (SuZ, p.121). Las consecuencias políticas - que no podemos desarrollar por motivos de extensión -, por ejemplo, de esta constatación son muy interesantes, por cuanto se destaca una igualdad que es original y fundante, permitiendo al otro aparecer, justamente, como otro. Ahora bien, a pesar del interés que pudiera generar la cuestión, nuestra investigación ya se ha topado con una definición de libertad más potente que aquella dada 
en referencia al ente intramundano como "dejar/poner en libertad" [freigeben/ Freigabe]. En buena medida, el fin de la solicitud anticipativa-liberadora, partiendo de una igualdad de corte ontológico, la cual no trata al otro bajo criterios de dominación e instrumentalidad, permite que el otro sea libre para ser lo que es, pudiendo llevar a cabo su existencia en los términos del propio Heidegger: existir es comprender ejecutivamente posibilidades temporales y finitas.

\section{Conclusión}

A modo muy sintético, conviene recolectar lo expresado en esta investigación, empezando por lo último manifestado: la solicitud anticipativoliberadora es la forma más eximia de libertad por la que el otro deviene "otro" siendo libre para lo que es. Pero esta posibilidad eminente de ser-uno-con-losotros, no hubiera sido posible si, antes, el Dasein no hubiera descubierto la radicalidad de su estado de apertura, el cual lo constituye en su ser. El estado de apertura, el modo como el Dasein es su Ahí, presuponía, pues, que este ente se abre, siempre ya, para sí mismo. Tal acto de apertura para sí-mismo, ya tanteada en el $\S 9$ bajo los existenciarios tener-que-ser y ser-en-cada-caso-mío, a través del saber denominado "transparencia" [Durschsichtigkeit], presuponía que tal Dasein tiene que ser su mismidad bajo la modalidad de recuperar una elección, una elección que lo pusiera como responsable de lo que es por y sobre todos los momentos constitutivos de su ser en tanto ser-en-el-mundo. Por tanto, la mismidad de la que hablamos, como acto de apertura de sí del Dasein, siempre ya ha de prevalecer en el "comportarse" [sich-Verhalten] en el mundo que es este Dasein. Solo de este modo, siendo sí-mismo, es posible hablar de libertad. Pero que no se olvide, libertad para el Dasein es también libertad del ente intramundano y libertad para/del otro.

\section{Referencias}

BERNASCONI, R.; WOOD, D. "The Provocation of Levinas. Rethinking the Other". London/New York: Routledge, 1988.

FIGAL, G. "Martin Heidegger. Phänomenologie der Freiheit". Frankfurt a. M.: Anton Hain, 1991.

Gadamer, H.G. "Wahrheit und Methode". En: Gesammelte Werke, Band 2, Tübingen: Mohr Siebeck 1993.

GARCÍA-NORRO, J.J. “El cuidado como el ser del Dasein”. En: Ser y Tiempo de Martin Heidegger. Un comentario fenomenológico. Ed. R. Rodríguez. Madrid: Tecnos, 2015:167-198. 
GARRIDO-PERIÑÁN, J.J. "La pregunta por el quién del ser-con: Heidegger en su Ser y Tiempo". Revista Anales del Seminario de Historia de la Filosofía, Vol. 39, Nr. 1, pp. 175-200, 2019a.

. "La aportación no-apofántica de la disposición afectiva y la mismidad del Dasein: análisis fenomenológico a partir del momento estructural ser-en". Pensamiento: Revista de Investigación e Información Filosófica, Vol. 75 (285), 887-911, 2019b.

."En busca del sí-mismo perdido del Dasein: un diálogo entre Kafka y Heidegger en torno a la cuestión de la culpabilidad y la mismidad". Endoxa: Series Filosóficas, Vol. 40, Nr. 2, pp. 159-182, 2017.

"Aperturidad e iluminación: el Dasein como ente iluminado. Aportaciones a Sein und Zeit de Martin Heidegger bajo el horizonte del claro el ser". Eikasia: Revista Interncional de Filosofía, Vol. 56, Nr. 2, pp. 203-216, 2016.

. "Ser y Lichtung: Heidegger ante el claro del ser. Desafíos fenomenológicos en torno al claro del ser". Madrid: Visión-Libros, 2015.

GUIGNON, Ch. "Heidegger's concept of freedom 1927-1930”. En: Interpreting Heidegger: Critical Essays. Ed. D. Dahlstrom. Cambridge/New York: Cambridge University Press, 2011, pp. 79-105.

HEIDEGGER, M. "Einführung in die phänomenologische, Forschung”. En: II. Abteilung, Band 17, Frankfurt a. M.: Vittorio Klostermann, 2006.

. "Sein und Zeit". Tübingen: Max Niemeyer, 2002.

. "Phänomenologie des Religiösen Lebens". En: II. Abteilung, Band 60, Frankfurt a. M.: Vittorio Klostermann, 1995.

. "Platon: Sophistes". En: II. Abteilung, Band 19, Frankfurt a. M.: Vittorio Klostermann, 1992.

. "Ontologie (Hermeneutik der Factizität)". En:II Abteilung, Band 63, Frankfurt a. M.: Vittorio Klostermann, 1988. 1976.

“Wegmarken”.En: I. Abteilung, Band 9, Frankfurt a. M.: Vittorio Klostermann,

. "Der Grundprobleme der Phänomenologie". En: II Abteilung, Band 24, Frankfurt a. M.: Vittorio Klostermann, 1975.

LEVINAS, E. "Totalidad e infinito. Ensayo sobre la exterioridad". Traducción al español de Antonio Pitor Ramos. Salamanca: Sígueme, 1999.

REIS, R. "El concepto existencial de ciencia". En: Guía Comares de Heidegger. Ed. R. Rodríguez. Granada: Editorial Comares, 2018, pp. 121-142.

SCHMIDT, S.W.: Grund und Freiheit. Eine phänomenologische Untersuchung des Freiheitsbegriffs Heideggers, Dordrecht, Springer, 2015.

THEUNISSEN, M. "Der Anderen Studien zur Sozialontologie der Gegenwart”. Berlin/ New York: De Gruyter, 1977.

VIGO, A. "Libertad como causa. Heidegger, Kant y el problema metafísico de la libertad”. Anuario Filosófico, Vol.XLIII, Nr. 1, 2010, pp. 61-181.

. "Verdad, libertad y trascendencia en Heidegger: la radicalización de un motivo central en Sein und Zeit en los escritos de los años 1929-1930". Arqueología y Aleteiología. Estudios heideggerianos. Berlin: Logos Verlag Berlin, pp. 159-205, 2014a. 
. "Afectividad, comprensión y lenguaje. Heidegger y la reconstrucción aleteiológica del discurso no apofántico". En: Arqueología y Aleteiología. Estudios heideggerianos. Berlin: Logos Verlag Berlin, 2014b, pp. 437-466.

. "El posible ser total del Dasein y el ser para (vuelto a) la muerte (§§ 45-53)". En: Ser y Tiempo de Martin Heidegger. Un comentario fenomenológico. Ed. R. Rodríguez. Madrid: Tecnos, 2016, pp. 219-268. 